\title{
Potential causal factors of CFS/ME: a concise and systematic scoping review of factors researched
}

\author{
Ashley Elizabeth Muller ${ }^{1 *} \mathbb{D}$, Kari Tveito ${ }^{2}$, Inger Johanne Bakken³, Signe A. Flottorp ${ }^{1,4}$, Siri Mjaaland \\ and Lillebeth Larun ${ }^{1}$
}

\begin{abstract}
Background: Chronic fatigue syndrome/myalgic encephalomyelitis (CFS/ME) is understood as a complex condition, likely triggered and sustained by an interplay of biological, psychological, and social factors. Little oversight exists of the field of causal research. This systematic scoping review explores potential causal factors of CFS/ME as researched by primary studies.
\end{abstract}

Methods: We searched eight databases for primary studies that examined potential causal factors of CFS/ME. Based on title/abstract review, two researchers independently sorted each study's factors into nine main categories and 71 subordinate categories, using a system developed with input given during a 2018 ME conference, specialists and representatives from a ME patient advocacy group, and using BMJ Best Practice's description of CFS/ME etiology. We also extracted data related to study design, size, diagnostic criteria and comparison groups.

Results: We included 1161 primary studies published between January 1979 and June 2019. Based on title/abstract analysis, no single causal factor dominated in these studies, and studies reported a mean of 2.73 factors. The four most common factors were: immunological (297 studies), psychological (243), infections (198), and neuroendocrinal (198). The most frequent study designs were case-control studies (894 studies) comparing CFS/ME patients with healthy participants. More than half of the studies (that reported study size in the title/abstract) included 100 or fewer participants.

Conclusion: The field of causal hypotheses of CFS/ME is diverse, and we found that the studies examined all the main categories of possible factors that we had defined a priori. Most studies were not designed to adequately explore causality, rather to establish hypotheses. We need larger studies with stronger study designs to gain better knowledge of causal factors of CFS/ME.

Keywords: Etiology, Scoping review, Patient involvement, Chronic fatigue syndrome, Myalgic encephalomyelitis

\section{Background}

$\mathrm{CFS} / \mathrm{ME}$ is a condition characterized by prolonged, significant, and sometimes disabling exhaustion and postexertion malaise, accompanied by symptoms such as

\footnotetext{
*Correspondence: aemu@fhi.no

${ }^{1}$ Norwegian Institute of Public Health, Skøyen, PO Box 222, 0213 Oslo, Norway

Full list of author information is available at the end of the article
}

generalized pain, sleep disorders, and cognitive problems [13, 24, 28]. Fatigue can be aggravated by physical and mental exertion, and does not decrease after rest [22, 28]. Rather than a single cause, it is likely that multiple biological, psychological and/or social factors may predispose, trigger, and maintain this condition [11]. Identifying potential causal factors is imperative to understanding CFS/ME and to developing more effective treatments and prevention.

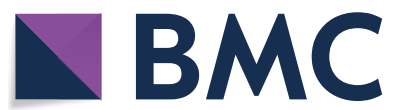

(c) The Author(s) 2020. This article is licensed under a Creative Commons Attribution 4.0 International License, which permits use, sharing, adaptation, distribution and reproduction in any medium or format, as long as you give appropriate credit to the original author(s) and the source, provide a link to the Creative Commons licence, and indicate if changes were made. The images or other third party material in this article are included in the article's Creative Commons licence, unless indicated otherwise in a credit line to the material. If material is not included in the article's Creative Commons licence and your intended use is not permitted by statutory regulation or exceeds the permitted use, you will need to obtain permission directly from the copyright holder. To view a copy of this licence, visit http://creativeco mmons.org/licenses/by/4.0/. The Creative Commons Public Domain Dedication waiver (http://creativecommons.org/publicdomain/ zero/1.0/) applies to the data made available in this article, unless otherwise stated in a credit line to the data. 
The vastness of the research field on etiological factors reflects the variety of causal hypotheses [19], and in the past two years alone, numerous systematic reviews have been published examining distinct causal factors such as immunological [12, 16, 29], metabolic [15, 23], circulatory [27], and epigenetic factors [3]. In 2016, the Research Council of Norway selected the CFS/ME field as the pilot field for a research priority setting partnership strategy, in which patients, next of kin, and related organizations prioritized research questions for commissioned research [14]. When topics for CFS/ME-related research proposals were requested [31], patients and next of kin submitted more than 700 submissions. Sixty percent of their submissions involved questions about causal factors. At the suggestion of the Research Council of Norway, we conducted a systematic scoping review of primary studies that examined predisposing, triggering and maintaining factors to CFS/ME.

\section{Methods}

A systematic scoping review presents an overview of research relating to a specific topic or question, without producing a summary answer to that question or assessing the methodological quality of primary studies $[4,33]$. This method was well-suited to this review's exploratory and descriptive aims. Following Arksey and O'Malley's framework for scoping reviews, we collaborated with a working group from the Norwegian ME Association to develop the research question as well as inclusion and exclusion criteria, and we published a protocol in Norwegian [25]. We included all primary studies, of any design besides case reports, that examined potential predisposing, triggering, and maintaining factors in patients with CFS/ME. We searched eight databases in June 2019 with free text words (in title and summary) and controlled terms for the patient group, combined with free text words and terms for cause/risk. We had no restrictions relating to year of publication or language. Additional file 1: Appendix S1 contains an overview of all databases searched as well as the search strategy for OVID. The PRISMA Checklist for Scoping Reviews is available in Additional file 2: Appendix S2.

Two researchers independently screened titles/ abstracts for inclusion using Covidence software [34]. In the event of disagreement or uncertainty, we consulted a third researcher. Using EPPI Reviewer [32], one researcher extracted data from titles/abstracts on diagnostic criteria, comparison group, study design, number of participants, and the region where the study was conducted (Table 1). We did not retrieve the full texts of the included studies, and we based the data extraction on the titles and abstracts only.

Two researchers independently categorized every potential causal factor using a system of nine major categories, 48 sub-categories, and 23 further subordinate categories, as specified in a codebook. We developed this

Table 1 Data categories extracted from titles/abstracts

\begin{tabular}{|c|c|c|}
\hline Abstract & Diagnostic criteria & Number of participants \\
\hline Yes & Not reported & $\leq 30$ \\
\hline No & CDC $1988[21]$ & $31-100$ \\
\hline WHO Region & CDC/Fukada 1994 [18] & $101-1000$ \\
\hline Eastern Mediterranean region & Canadian 2003 [9] & $\geq 1,001$ \\
\hline Not reported & International consensus criteria [10] & $\begin{array}{l}\text { Etiological factors (see Additional file 3: } \\
\text { Appendix S3 for the complete categorization } \\
\text { scheme) }\end{array}$ \\
\hline African region & Arabic Scale of Chronic Fatigue Syndrome [1] & Infections \\
\hline European region & Other & Immunological \\
\hline Region of the Americas & Study design & Neuroendocrinal/hormonal/metabolic \\
\hline South-East Asian region & Not reported & Genetic/epigenetic \\
\hline Western Pacific region & Case-control & Circulatory \\
\hline Multiple & Cross-sectional & Gastrointestinal \\
\hline Comparison group & Cohort (prospective, retrospective) & Neurobiological \\
\hline Not reported & Other & Psychological/psychosocial/socioeconomic \\
\hline Type unspecified & & Other factors \\
\hline \multicolumn{3}{|l|}{ Non-patient group } \\
\hline \multicolumn{3}{|l|}{ Other patient group } \\
\hline None & & \\
\hline
\end{tabular}

The seven categories of data extracted from titles/abstracts of included studies. The full categorization scheme, and results, of Etiological factors are presented in Additional file 3: Appendix S3 
coding system based on the description of CFS/ME in BMJ Best Practice [6], and supplemented with input from an ME conference in 2018, as well as from specialists and representatives from the ME Association. Figure 1 is a screenshot of an abstract in EPPI Reviewer, annotated to display coding.

The nine causal categories were infections, immunological, neuroendocrinal/hormonal/metabolic, genetic/ epigenetic, circulatory, gastrointestinal, neurobiological, psychological/psychosocial/socioeconomic and other factors. If a study reported multiple factors, we coded all factors, but each factor was mutually exclusive (that is, two categories were never required to describe one factor). Each main category had up to nine sub-categories. For example, we divided infections into bacteria, viruses, fungi, parasites, other and not reported. Most sub-categories had further subordinate categories; for example, viruses were further categorized human herpesvirus, Epstein-Barr virus, xenotropic murine leukemia virus, hepatitis virus, other, and not reported (Additional file 3: Appendix S3). We developed and refined the codebook continually during the first half of the project, with particular attention to patterns within other subordinate categories, such that common factors coded therein would be extracted and receive their own codes.

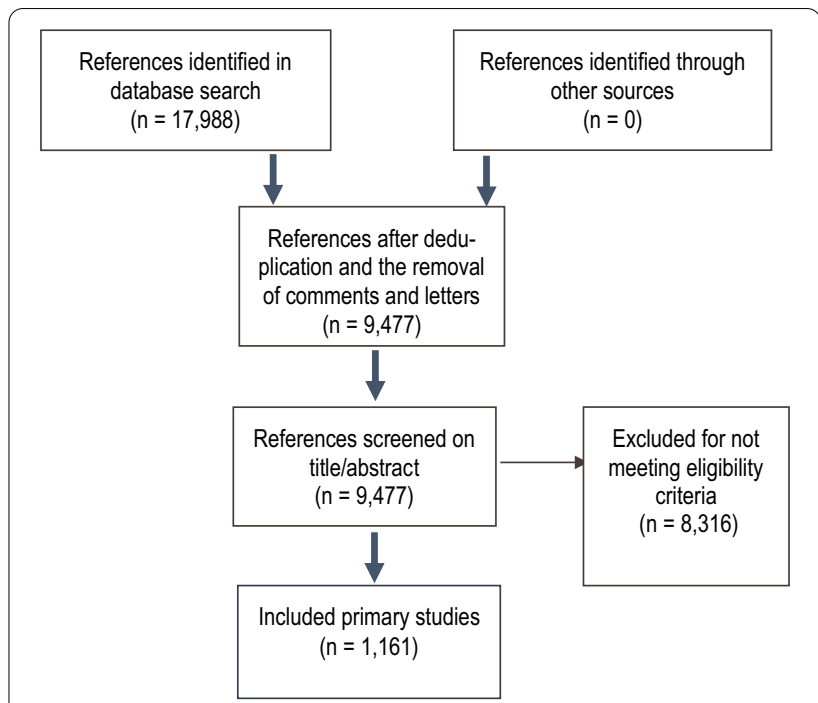

Fig. 2 Study flow diagram. A flow chart of the 9477 unique studies retrieved from database searches, of which 1161 met inclusion criteria after title/abstract review

\section{Results}

Figure 2 displays the results of the search and screening process. In total, 1161 studies were included (Additional file 4: Appendix S4).

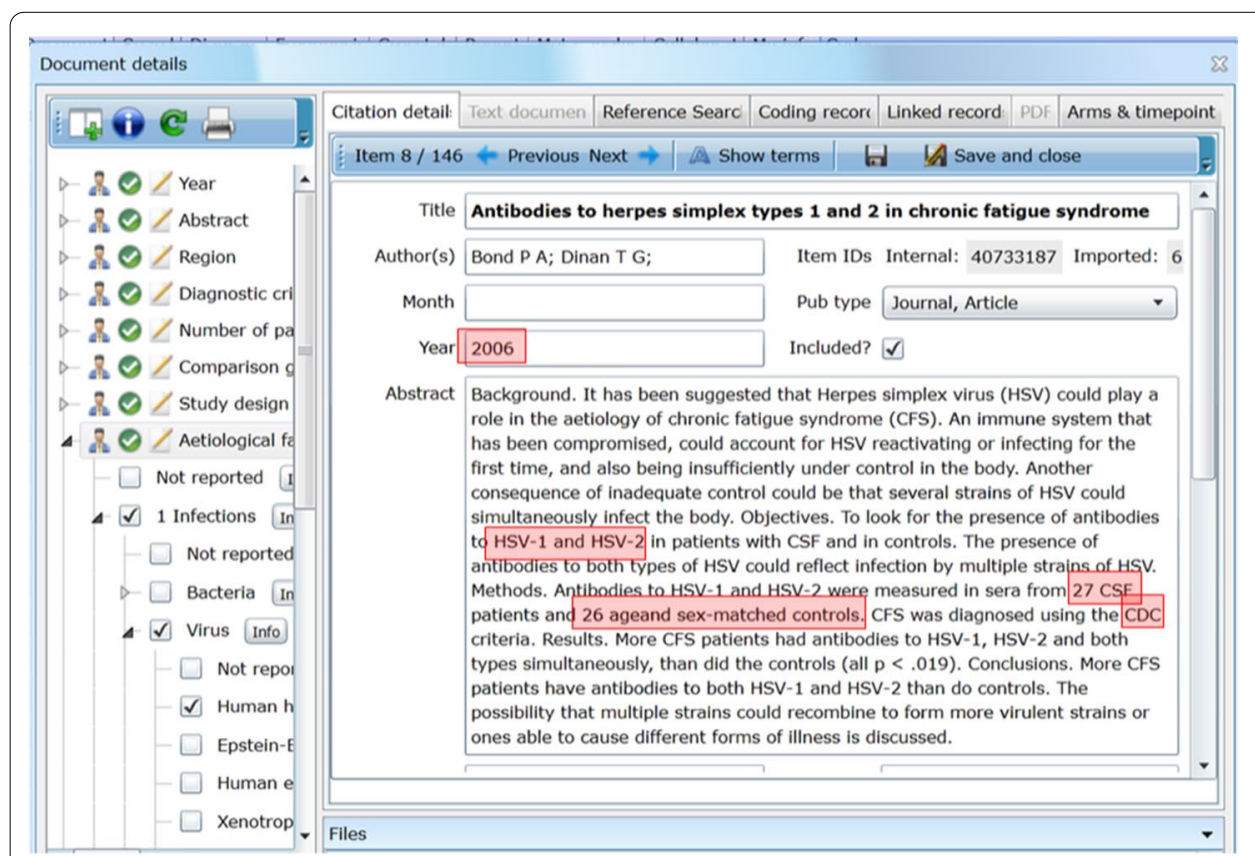

$\underline{\text { Coding }}$

Year: 2006

Abstract: Yes

Region: Not reported

Diagnostic criteria: $\mathrm{CDC} /$ Fukada

Number of participants: 27 CFS/ME, 26 other

Comparison group: Type not specified

Study design: Case-control

Etiological factor: Infections > Virus $>$ Human herpes virus

Fig. 1 An example of a fully coded study that reports the diagnostic criteria used, number of participants, study design, and one etiological factor 


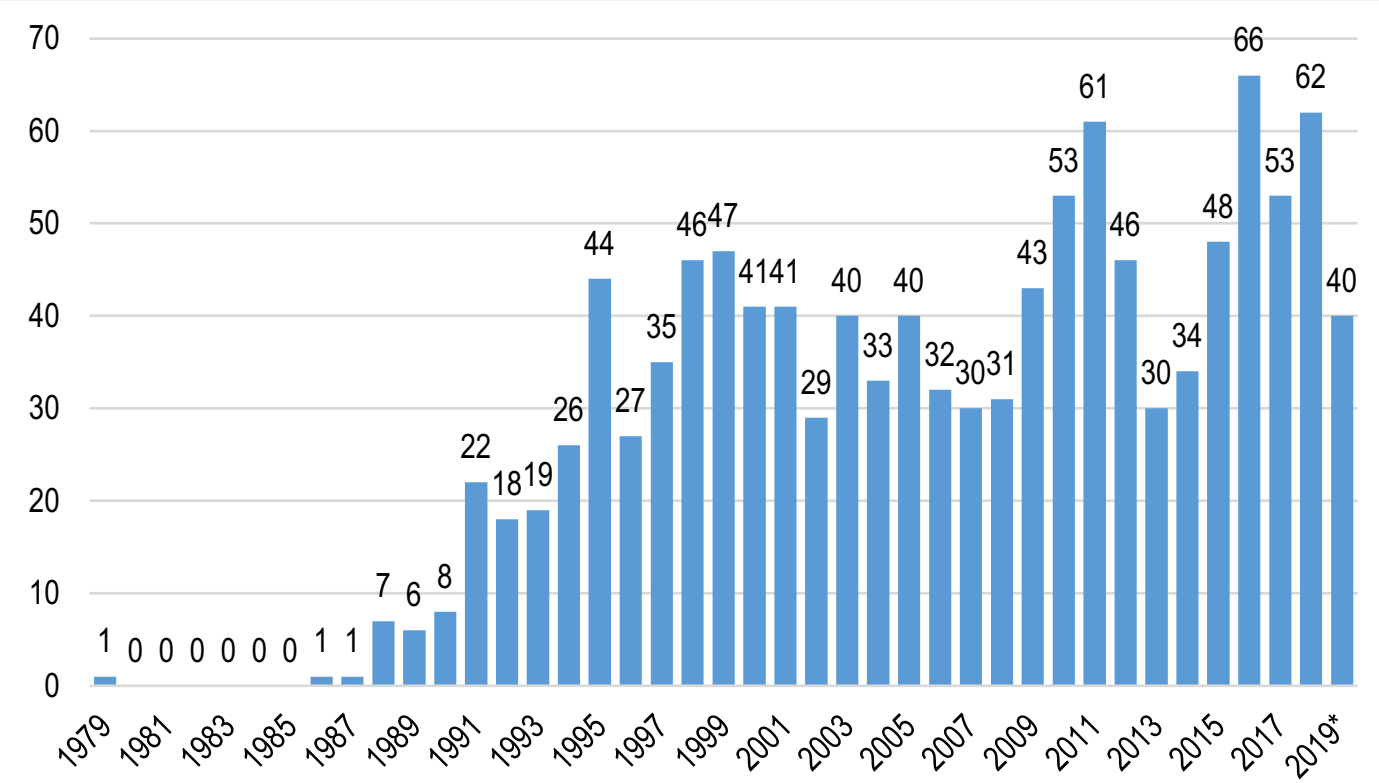

Fig. 3 Studies published per year, 1979-June 2019. *Published before June 2019. The number of studies published per year has increased steadily since the late 1980's, with at least 48 studies published yearly 2015-2019, and 40 published in the first half of 2019

\section{Characteristics of studies}

The number of published studies per year increased from one in 1979 to 40 from January to June 2019 (Fig. 3).

We extracted all data from the studies' titles and abstracts. Of 1161 studies, 68 were missing abstracts. Only 217 of the studies reported which diagnostic criteria were used in the titles/abstracts; 169 of these used the 1994 CDC/Fukada criteria [18]. Regarding study design, most studies (889) were case-control studies, in which CFS/ME patients were compared to some type of control or comparison group, at one point in time. There were 115 cross-sectional studies without a comparison or control group. A total of 67 studies were prospective or retrospective cohort studies. Fourteen studies fell into the category of "other" study design, which included twin studies, registry studies, and population-based screening studies. In 69 cases, study design was not reported in titles/abstracts.

A total of 679 prospective, retrospective, case-control, or "other" designs included comparison groups, and most used healthy/non-patient comparisons (61 to $66 \%$ of studies within each study design). Only 226 studies used other patient groups as comparisons. 181 studies used a comparison group but did not specify which type, and 73 did not report on comparison groups in titles/abstracts.

Study size varied considerably: in 117 studies, there were fewer than 30 participants, 440 had between 30-100 participants, 289 contained 101-1000 participants, and 31 contained more than 1000 participants. Cohort and "other" study designs were largest. Finally, only 170 studies stated in titles/abstracts the country in which they were conducted. Nearly half (87) were European, while 56 were conducted in North or South America.

\section{Potential causal factors examined}

Most studies examined several different potential causal factors (mean 2.73; range from 1 to 5 , out of a possible 9). The most frequently studied categories were immunological (272 studies), psychological/psychosocial/socioeconomic (243 studies), infections (198 studies) and neuroendocrinal/hormonal/metabolic (197 studies).

No single causal factor has dominated research in the field (Fig. 4). The number of studies on infection factors varied the most: it was the category with the largest number of studies before 1995 as well as in 2010-2014, but in the recent period of 2015-June 2019, there was a marked decrease. For all other categories, there was an increase in the number of studies from 2010 to 2019.

Additional file 3: Appendix S3 shows the number of studies in each category. For example, in the category of infections, there were 158 studies on CFS/ ME related to viruses, 35 about bacteria, three about parasites, one about fungal infections, six about other infections, and six that did not report the type of 


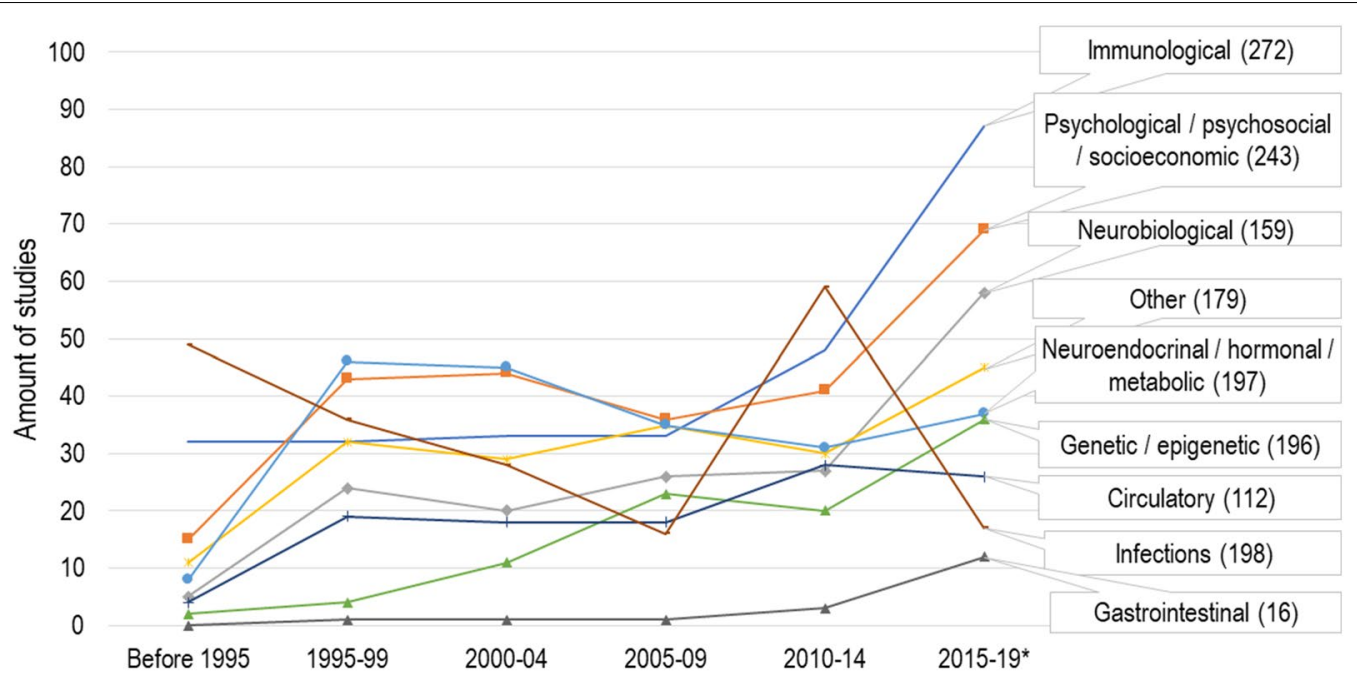

Fig. 4 The number of studies researching each potential causal factor in 5-year periods. *Number published before June 2019. Most potential causal factors, with the exception of infections, have been explored by an increasing number of studies since 2010. Some studies involved multiple factors and were counted in each category

virus. In the sub-category of viruses, there were 53 studies on the Epstein-Barr virus, 47 about human herpes virus, 29 about xenotropic murine leukemiarelated virus, five about other humane endogenous retroviruses, four about hepatitis virus, 70 about other viruses, and four that did not report type of virus.

\section{Discussion}

This systematic scoping review included 1161 primary studies on possible causal factors of CFS/ME, and we extracted data from titles and abstracts. Immunological, psychological, infections, and neuroendocrine factors have been most frequently studied. In most categories, there was a steady increase in the number of studies from 1994 and a slightly stronger increase from 2010 to 2019. Many studies were not limited to a single factor or causal hypothesis, but explored numerous factors, from environmental factors to genes. We did not find one dominant causal factor studied, and included studies reported a mean of nearly three different factors, which we interpret as a healthy diversity in the research field. As the number of published articles has increased steadily from 1979-2019, the variation of explored factors has also remained high. This indicates a great deal of uncertainty in the field, but the broad interest in diverse possible causal factors is positive.

A 2008 review included 11 studies that examined multiple possible "risk factors or prognostic flags" [20]. Our scoping review included 1161 studies, and although our scope was larger than the 2008 review, there is a clear increase in research in the field. However, our findings echo the conclusions of numerous recent reviews $[3,12$, $15,16,23,27,29]$, namely, that our confidence in the evidence is too low to draw conclusions about causal factors. This is due to the preponderance of relatively weak study designs. For most questions regarding etiology, we must rely on observational studies, as experimental trials randomly exposing people to hypothesized causal factors are rarely possible to conduct, and even if technically possible, would be unethical. Cross-sectional studies with or without comparisons or controls can provide evidence on correlations and help develop theories or hypotheses of causality, but are ill-suited to verify them. Most of the studies included were designed so that they were not suitable to detect causality, although many claimed this as their purpose. Even though studies might identify a correlation between a factor and a diagnosis, we cannot know if it is a signal of a causal factor, or a consequence of the diagnosis. We found no increase in the number of prospective, longitudinal studies being published over time. Prospective cohort studies following individuals that are exposed versus not exposed will provide stronger evidence on etiology than case control studies and retrospective cohort studies, but unmeasured confounding will inevitably lead to risk of bias, as in all observational studies.

In addition, more than half of the studies (that reported study size) included fewer than 100 participants, and around $60 \%$ of all studies compared CFS/ME patients with healthy controls-potentially inappropriate comparisons. If effect sizes are small, such small studies likely 
lack the statistical power to reveal differences between CFS/ME patients and other groups. However, determining statistical power of primary studies will only be possible with a full systematic review that examines studies in full-text. While it may be difficult to recruit enough patients with CFS/ME for studies, researchers need to prioritize prospective cohort studies with a sufficient number of participants. When enough data is collected to allow for advanced statistical techniques, sufficient comparison of individuals with different risks, exposure, and genetic variables is possible $[26,30]$; propensity score matching, for example, has been recently utilized in studies of other rare diseases and exposures [2].

An additional research challenge is the unambiguous diagnosis of CFS/ME using standard criteria. A systematic review from 2014 identified 20 different sets of diagnostic criteria [7]. CDC 1994/Fukuda criteria [18] were the most commonly used in that review, as in ours. This review did not find any evidence that some of the diagnostic criteria sets could identify conditions more likely with e.g. a specific organic etiology. In our sample based on titles/ abstracts, only $18 \%$ of studies reported which diagnostic criteria had been used. Some countries have registers of CFS/ME patients that are voluntarily organized and use combinations of self-report and symptom-based criteria (e.g. [8], while Norway and others use diagnostic codes (ICD-10, G.93.3) reported in broader nationwide registries [5]. As it is unclear if the type of diagnostic criteria or case definitions used influences the findings of primary studies, the way the patients are diagnosed should be clearly stated and, ideally, standardized in future studies [17].

\section{Strengths and limitations}

We searched in eight databases and used a broad and sensitive search strategy. One strength of the study is that a CFS/ ME patient advocacy group helped formulate the research questions and provided substantial input to the data extraction form and the causal factor categorization system. An overall strength of scoping reviews is that they provide a descriptive overview of existing research and knowledge gaps. A clear limitation of this review is that we extracted data from titles/abstracts only, and not from full-texts. While this was a pragmatic decision based on resources available, reading full texts would likely have provided us more information about study size, region, and comparison groups. It is important for readers to note that much of the data we report as "missing" from the title/abstract level may have been reported in full text. As we did not aim to synthesize the results of the studies, we think that the data extracted from the titles/abstracts provides the intended descriptive overview of the categories of causal factors that have been studied, and the study designs that have been used.

\section{Conclusion}

We saw a large variety of causal factors explored, although a precipitous decline in research on infections as causal factors in the past five years. It is problematic that research into causal factors of CFS/ME used different study designs, diagnostic criteria, control groups, and methods in general. Our scoping review shows that larger studies with stronger designs are needed. We hope to see more well-designed prospective cohort studies in the future, particularly as post-covid-19 fatigue-and the potential risk for developing CFS/ME after infection with Sars-CoV-2-is explored.

\section{Supplementary Information}

The online version contains supplementary material available at https://doi. org/10.1186/s12967-020-02665-6.

Additional file 1: Appendix S1. Search strategies and the databases we searched in June 2019 and December 2019.

Additional file 2: Appendix S2. Completed Preferred Reporting Items for Systematic reviews and Meta-Analyses extension for Scoping Reviews (PRISMA-SCR) Checklist.

Additional file 3: Appendix S3. The potential causal factors researched by 1,161 included primary studies, divided into nine main categories and 48 sub-categries. An additional 23 further subordinate categories are not shown, and are available by the authors upon request.

Additional file 4: Appendix S4. A list of all included 1,161 primary studies sorted alphabetically by main potential causal factor(s) researched.

\section{Abbreviation}

CFS/ME: Chronic fatigue syndrome/myalgic encephalomyelitis.

\section{Acknowledgements}

Our thanks to information specialists Ingvild Kirkehei and Elisabet Hafstad for the design and implementation of the literature searches, the Norwegian ME Association for input into the project design and other contributions, and Kjetil Gundro Brurberg for help in the project design and with screening.

\section{Authors' contributions}

$L L$ was the project leader. KT, SAF, SM, IJB, and LL were involved in the project design. KT, SAF, SM, and LL screened studies. AEM, KT, SAF, SM, and LL extracted data. AEM analyzed data. $L L$ and AEM drafted the first version of the manuscript. All authors contributed substantially to writing and interpretation of results. All authors read and approved the final manuscript.

\section{Funding}

No funding was received.

\section{Availability of data and materials}

Secondary data may be made available by the corresponding author upon request.

\section{Ethics approval and consent to participate}

Not applicable.

\section{Consent for publication}

Not applicable.

\section{Competing interests}

The authors declare that they have no competing interests. ICMJE forms for each author are available from the corresponding author upon request. 


\section{Author details}

${ }^{1}$ Norwegian Institute of Public Health, Skøyen, PO Box 222, 0213 Oslo, Norway.

2 Journal of the Norwegian Medical Association, Sentrum, PO Box 1152, 0107 Oslo, Norway. ${ }^{3}$ Norwegian Directorate of Health, Skøyen, PO Box 222, 0213 Oslo, Norway. ${ }^{4}$ University of Oslo, Oslo, Norway.

Received: 9 October 2020 Accepted: 4 December 2020 Published online: 14 December 2020

\section{References}

1. Abdel-Khalek A, Al-Theeb S. The construction and validation of the Arabic Scale of Chronic Fatigue. Derasat Nafseyah (Psychol Stud). 2006;16:11.

2. Almaghlouth I, Pullenayegum E, Gladman DD, Urowitz MB, Johnson SR. Propensity score methods in rare disease. A demonstration using observational data in systemic lupus erythematosus. J Rheumatol. 2020. https ://doi.org/10.3899/jrheum.200254.

3. Almenar-Pérez E, Ovejero T, Sánchez-Fito T, Espejo JA, Nathanson L, Oltra E. Epigenetic components of myalgic encephalomyelitis/chronic fatigue syndrome uncover potential transposable element activation. Clin Ther. 2019:41(4):675-98.

4. Arksey H, O'Malley L. Scoping studies: towards a methodological framework. Int J Soc Res Methodol Theory Pract. 2005;8(1):19-32.

5. Bakken IJ, Tveito K, Aaberg KM, Ghaderi S, Gunnes N, Trogstad L, Magnus P, Stoltenberg C, Håberg SE. Comorbidities treated in primary care in children with chronic fatigue syndrome/myalgic encephalomyelitis: a nationwide registry linkage study from Norway. BMC Fam Pract. 2016;17(1):128.

6. Baraniuk J. Chronic fatigue syndrome/Myalgic encephalomyelitisaetiology. BMJ Best Pract. 2018. https://bestpractice.bmj.com/topics/ en-gb/277/aetiology. Accessed Feb 2020.

7. Brurberg K, Fønhus MS, Larun L, Flottorp S, Malterud K. Case definitions for chronic fatigue syndrome/myalgic encephalomyelitis (CFS/ME): a systematic review. BMJ Open. 2014;7(2).

8. Buchwald D, Herrell R, Hartman S, Belcourt M, Schmaling K, Goldberg J. The chronic fatigue twin registry: method of construction, composition, and zygosity assignment. Twin Res. 1999;2:203-11.

9. Carruthers BM, Jain AK, De Meirleir KL, Peterson DL, Klimas NG, Lerner AM, Bested AC, Flor-Henry P, Joshi P, Powles ACP, Sherkey JA, van de Sande MI. Myalgic encephalomyelitis/chronic fatigue syndrome. J Chronic Fatigue Syndr. 2003;11(1):7-115

10. Carruthers BM, van de Sande MI, De Meirleir KL, Klimas NG, Broderick G, Mitchell T, Staines D, Powles ACP, Speight N, Vallings R, Bateman L, Baumgarten-Austrheim B, Bell DS, Carlo-Stella N, Chia J, Darragh A, Jo D, Lewis D, Light AR, Marshall-Gradisbik S, Mena I, Mikovits JA, Miwa K, Murovska M, Pall ML, Stevens S. Myalgic encephalomyelitis: international consensus criteria. J Intern Med. 2011;270(4):327-38.

11. CDC. Etiology and Pathophysiology. ME/CFS. 2018. https://www.cdc.gov/ me-cfs/healthcare-providers/presentation-clinical-course/etiology-patho physiology.html. Accessed 8 Aug 2020.

12. Corbitt M, Eaton-Fitch N, Staines D, Cabanas H, Marshall-Gradisnik S. A systematic review of cytokines in chronic fatigue syndrome/myalgic encephalomyelitis/systemic exertion intolerance disease (CFS/ME/SEID). BMC Neurol. 2019;19:207.

13. Cortes Rivera M, Mastronardi C, Silva-Aldana CT, Arcos-Burgos M, Lidbury BA. Myalgic encephalomyelitis/chronic fatigue syndrome: a comprehensive review. Diagnostics (Basel). 2019:9(3):91.

14. Crowe S. James Lind Alliance Priority Setting Partnerships. 2019. https ://methods.cochrane.org/prioritysetting/blog/james-lind-alliance-prior ity-setting-partnerships.

15. Du Preez S, Corbitt M, Cabanas H, Eaton N, Staines D, Marshall-Gradisnik S. A systematic review of enteric dysbiosis in chronic fatigue syndrome/ myalgic encephalomyelitis. Syst Rev. 2018;7(1):241.

16. Eaton-Fitch N, du Preez S, Cabanas H, Staines D, Marshall-Gradisnik S. A systematic review of natural killer cells profile and cytotoxic function in myalgic encephalomyelitis/chronic fatigue syndrome. Syst Rev. 2019:8(1):279.

17. Estevez-Lopez F, Mudie K, Wang-Steverding X, Bakken IJ, Ivanovs A, Castro-Marrero J, Nacul L, Alegre J, Zalewski P, Slomko J, Strand EB, Pheby D, Shikova E, Lorusso L, Capelli E, Sekulic S, Scheibenbogen C, Sepulveda N, Murovska M, Lacerda E. Systematic Review of the Epidemiological Burden of Myalgic encephalomyelitis/chronic fatigue syndrome across
Europe: current evidence and EUROMENE research recommendations for epidemiology. J Clin Med. 2020;9(5):1557.

18. Fukuda K, Straus S, Hickie I, Sharpe M, Dobbins J, Komaroff A. The chronic fatigue syndrome: a comprehensive approach to its definition and study. International Chronic Fatigue Syndrome Study Group. Ann Intern Med. 1994;121(12):953-9.

19. Harvey SB, Wadsworth M, Wessely S, Hotopf M. Etiology of chronic fatigue syndrome: testing popular hypotheses using a national birth cohort study. Psychosom Med. 2008;70(4):488-95.

20. Hempel S, Chambers D, Bagnall A-M, Forbes S. Risk factors for chronic fatigue syndrome/myalgic encephalomyelitis: a systematic scoping review of multiple predictor studies. Psychol Med. 2008;38(7):915-26.

21. Holmes GP, Kaplan JE, Gantz NM, Komaroff AL, Schonberger LB, Straus SE, Jones JF, Dubois RE, Cunningham-Rundles C, Pahwa S, et al. Chronic fatigue syndrome: a working case definition. Ann Intern Med. 1988;108(3):387-9.

22. Holtzman CS, Bhatia S, Cotler J, Jason LA. Assessment of post-exertiona malaise (PEM) in patients with myalgic encephalomyelitis (ME) and chronic fatigue syndrome (CFS): a patient-driven survey. Diagnostics (Basel). 2019:9(1):26

23. Huth TK, Eaton-Fitch N, Staines D, Marshall-Gradisnik S. A systematic review of metabolomic dysregulation in chronic fatigue syndrome/myalgic encephalomyelitis/systemic exertion intolerance disease (CFS/ME/ SEID). J Transl Med. 2020;18(1):198.

24. Institute of Medicine. Beyond myalgic encephalomyelitis/chronic fatigue syndrome redefining an illness. Washington, DC: National Academies Press (US); 2015.

25. Larun LK, Flottorp I, Mjaaland SA, Bakken S, Tveito IJ, Bruruberg KG. Prosjektplan for systematisk litteratursøk med sortering av primærstudier om årsaker til kronisk utmattelsessyndrom CFS/ME [Systematic literature list of the aetiology of chronic fatigue syndrome CFS/ME.]. 2017. https:// www.fhi.no/contentassets/99a31342c2ed48beaf53013889832d8d/prosj ektplan-cfs-arsak-systematsik-litteratursok-med-sortering.pdf. Accessed 6 Feb 2020.

26. Lim J, Walley R, Yuan J, Liu J, Dabral A, Best N, Grieve A, Hampson L, Wolfram J, Woodward P, Yong F, Zhang X, Bowen E. Minimizing patient burden through the use of historical subject-level data in innovative confirmatory clinical trials: review of methods and opportunities. Ther Innov Regul Sci. 2018;52(5):546-59.

27. Nelson JM, Bahl JS, Buckley JD, Thomson RL, Davison K. Evidence of altered cardiac autonomic regulation in myalgic encephalomyelitis/ chronic fatigue syndrome A systematic review and meta-analysis. Medicine (Baltimore). 2019;98(43):e17600.

28. Norwegian Directorate of Health. "CFS-ME." https://helsedirektoratet.no/ cfs-me. Accessed 30 Aug 2017.

29. Strawbridge R, Sartor ML, Scott F, Cleare AJ. Inflammatory proteins are altered in chronic fatigue syndrome-a systematic review and metaanalysis. Neurosci Biobehav Rev. 2019;107:69-83.

30. Sturmer T, Joshi M, Glynn RJ, Avorn J, Rothman KJ, Schneeweiss S. A review of the application of propensity score methods yielded increasing use, advantages in specific settings, but not substantially different estimates compared with conventional multivariable methods. J Clin Epidemiol. 2006:59(5):437-47.

31. The Norwegian Research Council (2019). User-identified research on CFS/ ME [Behovsidentifisert forskning om CFS/ME]. Oslo.

32. Thomas J, Brunton J, Graziosi S. EPPI-Reviewer 4: software for research synthesis. London: EPPI-Centre Software. Social Science Research Unit, UCL Institute of Education; 2010. p. 2020.

33. Tricco AC, Lillie E, Zarin W, O'Brien KK, Colquhoun H, Levac D, Moher D, Peters MDJ, Horsley T, Weeks L, Hempel S, AkI EA, Chang C, McGowan J, Stewart L, Hartling L, Aldcroft A, Wilson MG, Garritty C, Lewin S, Godfrey CM, Macdonald MT, Langlois EV, Soares-Weiser K, Moriarty J, Clifford T, Tunçalp Ö, Straus SE. PRISMA extension for scoping reviews (PRISMA-SCR): checklist and explanation. Ann Intern Med. 2018;169(7):467-73.

34. Veritas Health Innovation Covidence systematic review software. Melbourne, Australia.

\section{Publisher's Note}

Springer Nature remains neutral with regard to jurisdictional claims in published maps and institutional affiliations. 